Bangladesh J. Bot. 42(1): 131-137, 2013 (June)

\title{
ADAPTIVE ANATOMICAL STRUCTURE FOR NASTIC MOVEMENT IN MIMOSA PUDICA L.
}

\author{
Ming-Lin Chen*, Wen-Bin Mao and Mei-Chen Cui \\ Provincial Key Laboratory of Biotic Environment and Ecological Safety in Anhui, College of Life \\ Sciences, Anhui Normal University, Wuhu, 241000, Anhui Province, PRC
}

Key words: Mimosa pudica. Albizia julibrissin, Nastic movement, Reticulate lacuna, Petiole, Pulvinus

\begin{abstract}
In order to study the adaptive anatomical structures during nastic movement of Mimosa pudica L., anatomical structures of main pulvinus, common petioles, rachis and leaflets were compared with Albizia julibrissin Durazz. (taken as control). The anatomical structures of main pulvinus and common petiole of $M$. pudica were different from that of A. julibrissin. Upon stimuliti, the protoplast volume of $M$. pudica in the lower cortical parenchyma cells become smaller than that in upper ones, a feature seldom found in $A$. julibrissin. There were found many reticulate lacunas on the two side of adaxial petiole of $M$. pudica, but nil in A. julibrissin. Similarly some ill developed lacunas were found in the pulvinus of rachis and leaflet of $M$. pudica, but absent in A. julibrissin. It appears that reticulate lacunas in common petiole of $M$. pudica are responsible for its strong nastic movement. The main sensitivity position lies at the base of common petiole, where the lower cortex is more sensitive than the upper cortex, and the ordinal sensitivity positions are rachis and leaflets.
\end{abstract}

\section{Introduction}

The great curiosity of Mimosa pudica L. (Fabaceae) is that the compound leaves fold inward and droop when touched, warmed, blowed, shaken or traumatic, re-opening minutes later (Roblin 1979, Pierrette and Bonnemain 1978, Milne and Beamish 1999). The leaves also droop at night, and when exposed to rain or excessive heat. The response may be defensive against herbivorous insects, leaching loss of nutrients, or desiccation (Nilesh et al. 2009).

Albizia julibrissin Durazz. is also widely known as "Mimosa" and "Persian silk tree". Although once included in Mimosa, it has not the nastic movement like M. pudica (http://gardens.co.nz/PlantoftheWeek.cfm? NLID=96).

For M. pudica many opinions or hypothesis on the causes of leaf movements were proposed, which are: (i) Osmoregulation hypothesis: it was thought that the rapid bending movement of the main pulvinus of $M$. pudica is caused by a sudden loss of turgor pressure (Pfeffer 1905) and leaf movements occurred due to the transfer of $\mathrm{K}^{+}, \mathrm{Cl}^{-}, \mathrm{H}^{+}$, accompanied with the change of water and osmotic pressure (Fromm and Eschrich 1990, Salisbury and Ross 1992). (ii) Ion channel hypothesis: $\mathrm{Ca}^{2+}$ as second messenger played important role in message transfer of plant cells. Some authors thought that the pulvinus and leaf movements were correlated with $\mathrm{Ca}^{2+}$ transmembrane conductance (Toriyama and Jaffe 1972, Roblin and Fleurat-Lessard 1984, Schwartz 1985). (iii) Cytoskeleton hypothesis: some thought it was actin filaments that took part in the stimulative movements of $M$. pudica (Fleurat-Lessard et al. 1988).

Although Fleurat-Lessard and Roblin (1982) reported the histocytology of $M$. pudica, but seldom comparative study was reported on each joint points of pulvinus, petiole, rachis and leaflet in $M$. pudica. The objective was to study the adaptive mechanism between the movement function and the anatomical structures of M. pudica taking A. julibrissin as a control.

*Author for correspondence: <chenminglin0553@yahoo.com.cn>. 


\section{Materials and Methods}

Living plants of M. pudica and A. julibrissin growing in the mountains of Wuhu city, Anhui province, PRC were used.

For light microscopic observation, main pulvinus, common petioles, rachis and leaflets were sampled from the plants of $M$. pudica and A. julibrissin. After fixing in FAA, the samples were passed through 20,30, 40, 50, 60, 70, 80, 90 and 100\% ethyl alcohol to dehydrate the tissues for three hours at each concentration, then sectioned at the positions of a, b, c, d, e (Fig.1) in the two plants at a thickness of 6 - $8 \mu \mathrm{m}$ following the method described by Li (1987). The thin-sections were stained by safranin-fast green and observed under Olympus BX-UCB light microscope.
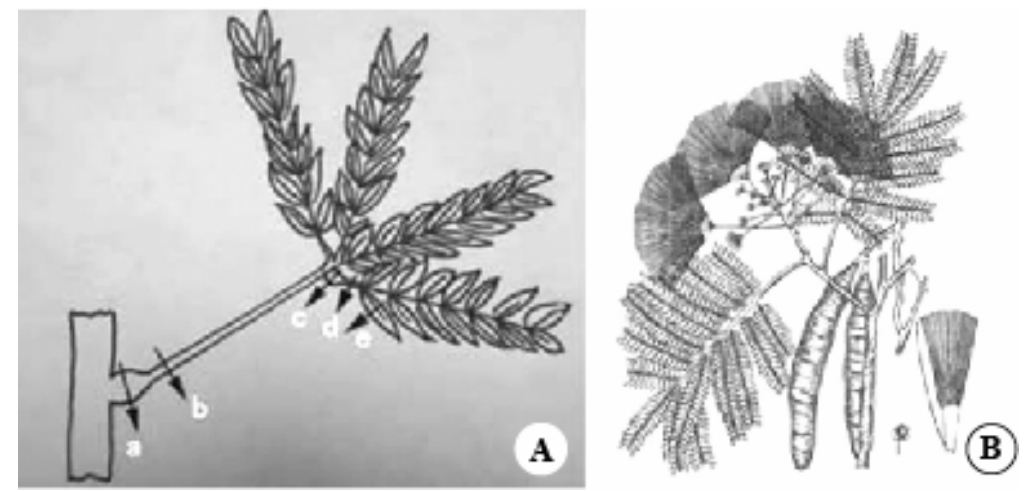

Fig. 1A-B: The transection positions in the leaf of $M$. pudica (A) and A. julibrissin (B). (a. main pulvinus, b. common petiole, c. pulvinus of rachis, d. rachis, e. leaflet).

Considering the difficulties in collecting the materials of $M$. pudica under no stimulation, $A$. julibrissin belonging to the same family was selected for the comparison. The anatomical characters of main pulvinus, common petiole, pulvinus of rachis, rachis and leaflet of the two plants were close to each other, thus use of A. julibrissin as control was reasonable for the experiment.

\section{Results and Discussion}

The shape of transection of main pulvinus of $M$. pudica and A. julibrissin presented proximal circular. The anatomical structures of the two species from outside to inside were identified following three regions of tissues: epidermis, cortex and vascular cylinder (Fig. 2A, B). The epidermis of the two species consisted of a single layer of quadrate cells which are closely packed (Fig. 2A, B). The cortex of M. pudica, which accounted for three fourth of the radii of transection, was located to the inside of the epidermis, and constitutes about 20 layers of big parenchyma cells. At the same time, the protoplast in lower cortical parenchyma cells was found smaller than that in upper ones $(\mathrm{P}<0.05, \mathrm{~N}=30)$. The diameter of protoplast in lower and upper parts were $8.67 \pm$ $1.14 \mu \mathrm{m}$ and $9.59 \pm 1.99 \mu \mathrm{m}$, respectively. Moreover, almost no crystals were found in the parenchyma cells (Fig. 2A). The cortex of A. julibrissin, whose proportion was less than that of $M$. pudica, accounted for about two-thirds the radii of transection, but no difference was found between the protoplast in bulk in upper and lower cortex. In addition, many crystals were found in parenchyma cells. The vascular cylinder of M. pudica was egg-shaped. It had almost no pith, only some parenchyma and pith rays. The vascular cylinder of A. julibrissin consisted of collateral 
vascular bundles, pith and pith rays. Many tenuous collateral vascular bundles and alternately arrayed tenuous pith ray circled the lunate pith with gap towards the adaxial pulvinus.
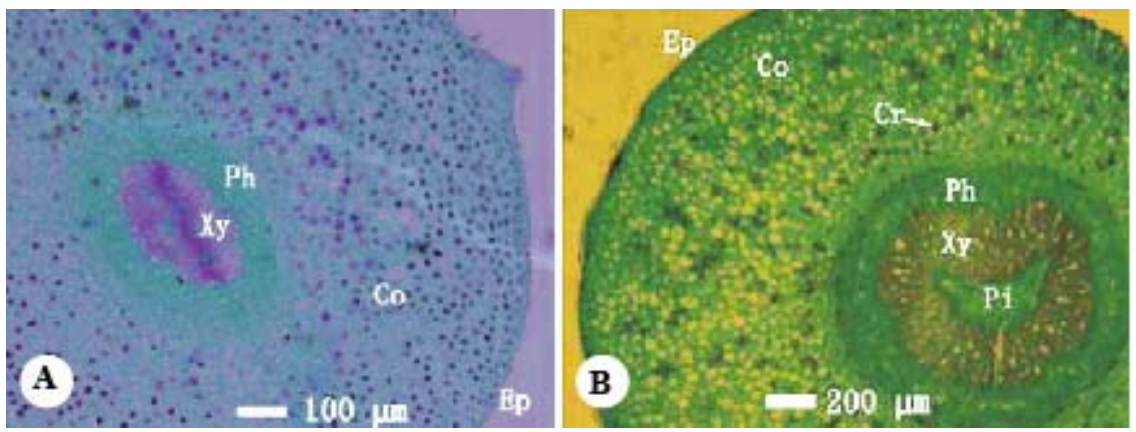

Fig. 2A-B: Main pulvinus of M. pudica (A) and A. julibrissin (B). (Ep = epidermis, Co = cortex, $\mathrm{Cr}=$ crystal, $\mathrm{Ph}=$ phloem, $\mathrm{Pi}=$ pith, $\mathrm{Xy}=$ xylem).

Aimi $(1960,1963)$ found that upon stimulation there was an irritable contraction both in the upper and the lower half of the main pulvinus. While Oda and Abe (1972) observed that bending movement of the main pulvinus was caused by the action potential and contraction of the lower half of the main pulvinus. Based on the observation, except for the difference of layers of parenchyma cells between the two species, the anatomical structure of pulvinus was similar, and there was almost no difference of intercellular spaces between the upper and lower tissues of main pulvinus of M. pudica, but the present results of less protoplast in volume in lower part of cortex cells in main pulvinus of M. pudica supported that this stimulus caused a loss of turgor in the cells composing the lower side of the pulvinus (Pfeffer 1905, Allen 1969), and it was thought that these movements resulted from the deformation of pulvinus due to various events taking place in their abaxial cortical parenchyma (especially transfer of $\mathrm{K}^{+}, \mathrm{Cl}^{-}$, and water) (Mahmoud 2011), i.e., when the plant is disturbed, the lower side of pulvinus is stimulated to release chemicals including potassium ions which forces water out of the cell vacuoles and the water diffuses out of the cells, producing a loss of cell turgor pressure and cell collapse; this differential turgidity between the upper and lower part of cells results in the bending movements.

The transection of common petiole of $M$. pudica was lunette (Fig. 3A). Compared to the epidermal cells, the parenchyma cells of cortex were bigger. Many reticulate lacunas were found on both sides of cortex of adaxial petiole, whose parenchyma cells were big and irregular, usually called motor tissues, but the reticulate lacuna in the abaxial side was not as that of the adaxial side. Vascular cylinder consisted of four collateral vascular bundles, pith and pith rays. It was found to have a few layered thick-walled libriform fibers forming a sheath around the vascular cylinder and motor tissues. The adaxial part of the phloem are without or with a few under developed fibres, while the abaxial part of the phloem was with well-developed fibres. The transection of common petiole of A. julibrissin appeared nearly pentagonal to nearly circler. No lacunas were found in the region of cortex (Fig. 3B), but many crystals in the parenchyma cells of cortex. The vascular bundle in adaxial side was different from those in the abaxial side. Compared to $M$. pudica, the libriform fibers from a circle sheath around phloem. The shape of pith and pith rays were arranged like a butterfly.

Fleurat-Lessard and Roblin (1982) showed existance of different structures between the pulvinus and petiole in $M$. pudica, and specialized structures facilitated leaf movements. The bending of common petiole and closed leaflets was due to loss of water on inclusion from some 
cells. Except for aquatic plants, in most of the normal vegetative organ cells of woody plants are packed closely without intercellular spaces, where the water or inclusions has gone is still unclear (Fleurat-Leassard and Roblin 1982). The present study showed there existed obvious differences in positions of common petiole of M. pudica. i.e., there existed lots of meshy cavities which may be related with the temporary storage of water or inclusions in the adaxial cortex, while no ones were found in A. julibrissin. So it was thought that the nastic movement might be related with the change of turgor pressure of cell located in the positions of common petiole in the experiment. When upon the external stimulation, the osmosis of adaxial cortex cell of common petiole enlarges, which results in the water or inclusions flow into the meshy cavities, so the turgor pressure descends and tissue turns soft; while because of the water penetration, the abaxial cortex cells present filling condition, so the common petiole droop, which was inferred that the effective position of bending movements was at the base of the petiole.
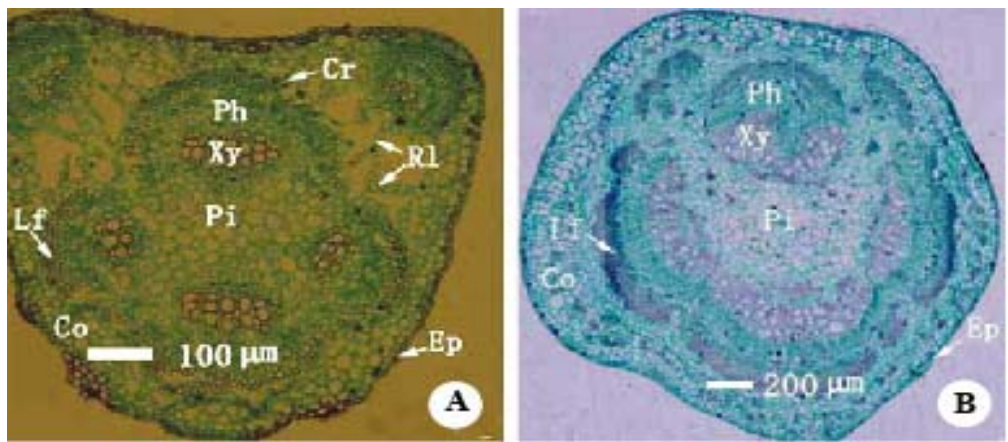

Fig. 3A-B: Transections of ommon petiole of $M$. pudica (A) and A. julibrissin (B). (Ep = epidermis, $\mathrm{Co}=$ cortex, $\mathrm{Cr}=$ crystal, $\mathrm{Lf}=$ libriform fibre, $\mathrm{Ph}=$ phloem, $\mathrm{Pi}=$ pith, $\mathrm{Rl}=$ reticulate lacuna, $\mathrm{Xy}=$ xylem.

The cross sections of pulvinus of rachis of the two species were almost circular like that of main pulvinus (Fig. 4A-B). Both the epidermis were made of a single layer of small quadrate cells. The cortex of $M$. pudica was made of 11-15 layers parenchyma cells. The vascular cylinder was ellipse or egg-shaped where the vessel members were obvious and arranged radially. The pith was composed of some radially arranged parenchyma cells. Compared to M. pudica, the cortex proportion of A. julibrissin was smaller with many rhombus- or cuboid-shape crystals (Fig. 4B). The vessels were composed of smaller cells inside and bigger ones outside, forming a ring in vascular bundle, were less developed in the $M$. pudica.
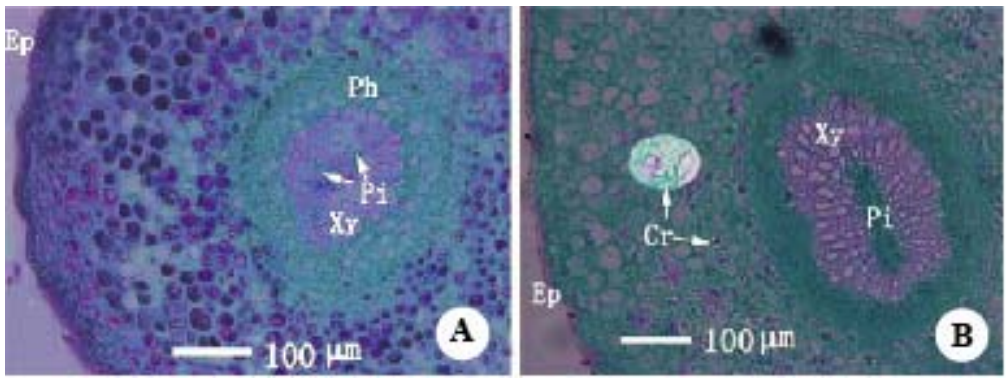

Fig. 4A-B: Transections of pulvinus of rachis of M. pudica (A) and A. julibrissin (B). $(\mathrm{Ep}=$ epidermis, $\mathrm{Co}=$ cortex, $\mathrm{Cr}=$ crystal, $\mathrm{Ph}=$ phloem, $\mathrm{Pi}=$ pith, $\mathrm{Xy}=$ xylem $)$. 
The upper part of the cross section of rachis of the two species appeared slightly concave, and the lower part wedge-circular shaped (Fig. 5A, B). The vascular cylinders of the two species were surrounded by closely packed sheaths consisting of several circuler sclerenchyma cells. In $M$. pudica two vascular bundles in the abaxial side of rachis and one semicircular vascular bundle on the adaxial side were found. In A. julibrissin, only one cordiform vascular bundle, presence of reticulated lacuna between the two small vascular bundles and absence of cristals in the contex distinguishes $M$. pudica.
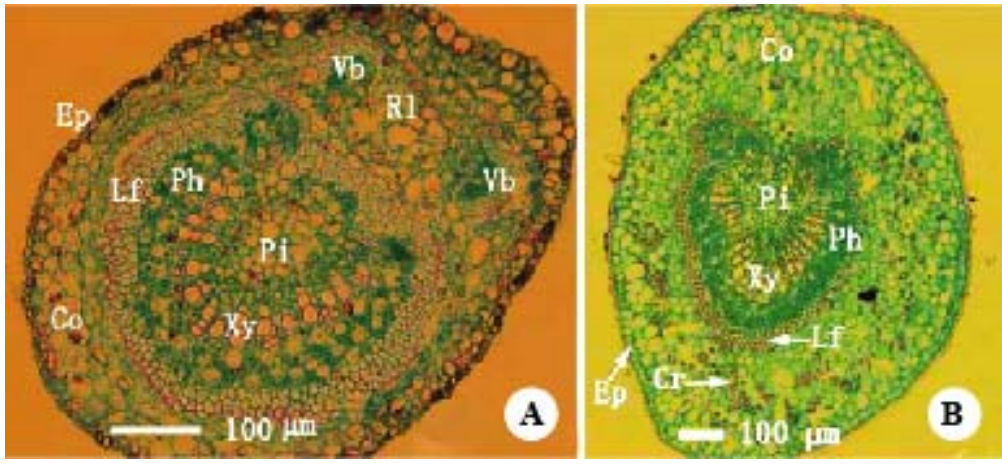

Fig. 5A-B: The transection of rachis of $M$. pudica (A) and A. julibrissin (B). Ep = epidermis, $\mathrm{Co}=$ cortex, $\mathrm{Vb}=$ vascular bundle, $\mathrm{Cr}=$ crystal, $\mathrm{Lf}=$ libriform fibre,, $\mathrm{Ph}=$ phloem, $\mathrm{Pi}=$ pith, $\mathrm{Rl}=$ reticulate lacuna, $\mathrm{Xy}=$ xylem.

The mesophyll tissue was composed of palisade in the upper and spongy tissues in the lower part of a transection in both plants (Fig. 6A,B). Some lacunas were distributed in the cavernous tissues, unlike the common petiole in $M$. pudica. The P/S (palisade tissues thickness/spongy tissues thickness) values of $M$. pudica and A. julibrissin 1.79 and 2.39, respectively. Seldom intercellular spaces were found in the mesophyll of M. pudica but it was absent in A. julibrissin. Moreover, many crystal cells were found surrounding the vein of $A$. julibrissin, but seldom in $M$. pudica.

Some study showed that the thickness ratio of palisade and sponge tissue was closely related with water-loss, i.e., the more the P/S value, the less water-loss (Fei et al. 1999). So it was predicted that water more easily flow in M. pudica than in A. julibrissin. When suffered with outside stimulation, the infiltration pressure of upper mesophyll enlarged, and water flew into the cell gap of lower mesophyll cell layer, so turgor pressure of adaxial cell descended, tissue became soft, but water was filled among the abaxial cells, so cells showed filled condition, which resulted in leaf close.
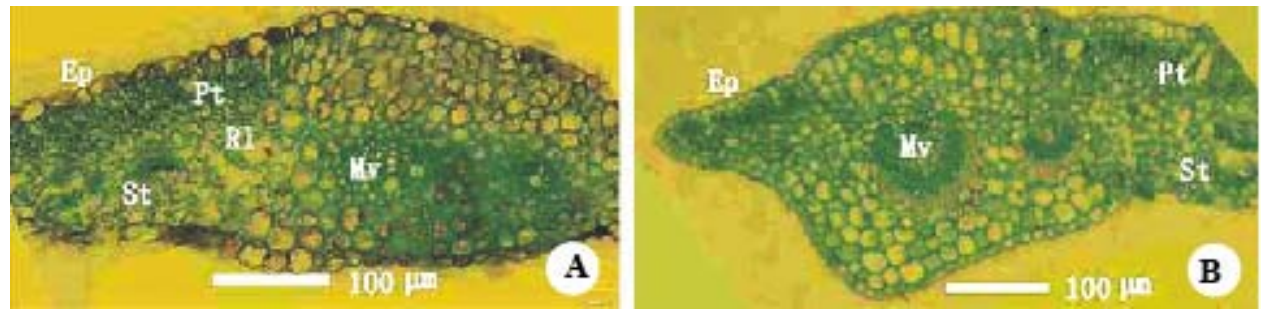

Fig. 6A-B: The transections of leaflet of $M$. pudica (A) and A. julibrissin (B). $(\mathrm{Ep}=$ epidermis, $\mathrm{Mv}=$ main vein, $\mathrm{Pt}=$ palisade tissues, $\mathrm{Rl}=$ reticulate lacuna $), \mathrm{st}=$ spongy tissues $)$. 
Structurally M. pudica adapted to the nastic movement. Its main sensitivity position lies at the base of common petiole but not in the main pulvinus, where the lower cortex is more sensitive than the upper cortex, and the ordinal sensitivity positions were rachis and leaflets. The typical reticulate lacuna to the adaptive anatomical structure in $M$. pudica.

\section{Acknowledgements}

The authors gratefully acknowledge the financial support from the Scientific Foundation of Anhui Province, China (11040606M72); the Provincial Key Nature Scientific Fund of Anhui, China (KJ2012A130); the Opening Fund for Provincial Key Laboratory and Key Discipline of Colleges of Life Sciences in Anhui Normal University (AHNU), China and the Special Fund of AHNU (2009xzx14).

\section{References}

Aimi R 1960. Studies on the mechanism of seismonastic leaf movement in Mimosa pudica L. 1. Existence of irritability in the upper half of the main pulvinus. Botanical Magazine (Tokyo) 73: 412-416.

Aimi R 1963. Studies on the irritability of the pulvinus of Mimosa pudica. Botanical Magazine (Tokyo) 76: 374-380.

Allen RD 1969. Mechanism of the seismonastic reaction in Mimosa pudica. Plant Physiol. 44: 1101-1107. Barneby RC 1991. Sensitivae censitae: a description of the genus Mimosa Linnaeus (Mimosaceae) in the New World. Mem. N. Y. Bot. Garden 65:1-835.

Fei SL, Fang JY, Fan YJ, Zhoo K, Liu XY and Ciu KM 1999. Anatomical characteristics of leaves and woods of Fagus lucida and their relationship to ecological factors in mountain Fanjingshan, Guizhou, China. Acta Botanica Sinica 41(9): 1002-1009.

Fleurat-Leassard P and Roblin G 1982. Comparative histocytology of the petiole and the main pulvinus in Mimosa pudica L. Ann. Bot. 50(1): 83-92.

Fleurat-Lessard P, Roblin G, Bonmort J and Besse C 1988. Effects of colchicine, vinblastine, cytochalasin B and phalloidin on the seismonastic movement of Mimosa pudica leaf and on motor cell ultrastructure. J. Exp. Bot. 39: 209- 221.

Fromm J and Eschrich W 1990. Seismonastic movement in Mimosa in the pulvinus. In: Satter RL, Gorton H, Vogelmann TC (eds). Motor Organ for Leaf Movement. Maryland: Am Soc. Plant Physiol. pp. 25- 43.

http://gardens.co.nz/PlantoftheWeek.cfm?NLID=96

Li ZL 1987. Techniques in Paraffin Section Cutting (in Chinese), Beijing: Science Press.

Mahmoud Raeini-Sarjaz 2011. Circadian rhythm leaf movement of Phaseolus vulgaris and the role of calcium ions. Plant Signal Behavior 6(7): 962-967.

Milne A and Beamish T 1999. Inhalational and local anesthetics reduce tactile and thermal responses in Mimosa pudica. Canadian J. Anesthesia 46(3): 287-289.

Nilesh K, Palwinder K, Kuntal D and Sudipta C 2009. Mimosa pudica L. a sensitive plant. Intl. J. Pharmacy Pharmaceutical Sci. 1(2): 1-7.

Oda $\mathrm{K}$ and Abe T 1972. Action potential and rapid movement in the main pulvinus of Mimosa pudica. Botanical Magazine (Tokyo) 85: 135-145.

Pfeffer W 1905. The physiology of plants 3 (Translated into English by A.J. Ewart.) Oxford; Clarendon Press.

Pierrette FL and Bonnemain JL 1978. Structural and ultrastructural characteristics of the vascular apparatus of the sensitive plant (Mimosa pudica L.). Protoplasma 94: 127-143.

Roblin B and Fleurat-Lessard P 1984. A possible mode of calcium involvement in dark- and light-induced leaflet movements in Cassia fasciculata Michx. Plant Cell Physiol. 25: 1495-1499.

Roblin G 1979. Mimosa pudiea: a model for the study of the excitability in plants. Biological Rev. 54: 135153. 
Salisbury FB and Ross CW 1992. Plant Physiology. pp. 408- 437, Belmont, Wadsworth Publishing Co., California.

Schwartz A 1985. Role of $\mathrm{Ca}^{2+}$ and EGTA on stomatal movements in Comellina communis L. Plant Cell Physiol. 79: 1003-1005.

Toriyama H and Jaffe MJ 1972. Migration of calcium and its role in regulation of seismonasty in motor cell of Mimosa pudica L. Plant Physiol. 49: 72- 81.

(Manuscript received on 29 September, 2011; revised on 23 March, 2013) 